\title{
EVERYDAY PRACTICES OF SANITATION UNDER UNEVEN URBAN DEVELOPMENT IN CONTEMPORARY SHANGHAI
}

\author{
Dr Deljana lossifova, deljana.iossifova@manchester.ac.uk \\ School of Environment, Education and Development \\ University of Manchester
}

\section{This article is forthcoming in Environment and Urbanization.}

\begin{abstract}
China has seen rapid economic development and urbanisation and this has included the upgrading of traditional sanitation systems. But the speed of this transition raises concerns about the coexistence of diveroging sanitation practices and their impact. This paper asks how this coexistence is experienced by low-income urban residents in Shanghai. It is based on field research during four weeks in July 2013 which involved in-depth, open-ended interviews with 20 low-income urban residents. The article concludes that these diverging everyday practices are situated at the core of urban socio-spatial differentiation, inequality, exclusion and discrimination. Particularly affected are rural-to-urban migrrants and aggeing working-class residents for whom the lack of access to improved sanitation may be associated with stiogmatisation and social isolation. Future research should examine how changing sanitation cultures under urban development and diveroging sanitation practices in different contexts can affect family ties, social relations and socio-spatial integration.
\end{abstract}

Keywords: Shanghai, urban development, coexistence, sanitation, differentiation

\section{INTRODUCTION}

Ever since "Opening Up and Reform" began in 1978, China has seen rapid economic development and urbanisation. The encroachment of urban sprawl upon agricultural land and villagges' and the on-gुoing replacement of old and impoverished urban neighbourhoods (home to the urban poor and rural-to-urban migrants) with new-built gated communities for an emeroging middle class in the country's cities ${ }^{2}$ have led to the coexistence of very diverse urban groups in what Wissink and

\footnotetext{
'Wu, Fulong, Fangzzhu Zhang and Chris Webster (2013). "Informality and the Development and Demolition of Urban Villages in the Chinese Peri-urban Area." Urban Studies 50(10): 1919-1934.

${ }^{2}$ He, Shenjing (2007). "State-sponsored Gentrification under Market Transition: The Case of Shanghai." Urban Affairs Review 43(2): 171-198, ibid., He, Shenjing and Fulong Wu (2007). "Socio-spatial impacts of property-led redevelopment on China’s urban neighbourhoods." Cities 24(3): 194-208, Wu, Fulong (2009). "Neo-urbanism in the making under China's market transition." City 13(4): 418-431, Wu, Fulong (2010). "Gated and packagुed suburbia: Packagुing and branding Chinese suburban residential development." Cities 27(5): 385-396, Wu, Qiyan, Jianquan Cheng, Guo Chen, Denial J Hammel and Xiaohui Wu (2014). "Socio-spatial differentiation and residential segुregation in the Chinese city based on the 2000 community-level census data: A case study of the inner city of Nanjing." Ibid. 39: 109-119.
} 
colleagues refer to as "patchworked, unifunctional, and monocultural enclaves" ${ }^{3}$ This coexistence of old and new, rich and poor, old and young - an expression of escalating social, economic and spatial inequalities - includes the coexistence of various systems of sanitation and the diveroging practices of sanitation associated with them.

Although it has been suogosested that the spaces in-between 'enclaves' can play a positive role in the negotiation of urban coexistence, ${ }^{4}$ the impact of diverging everyday practices of sanitation on long- and short-term differentiation in the transitioning Chinese city has remained largyely unexplored. This paper, therefore, asks how the coexistence of diveroging sanitation practices under conditions of rapid urban development is experienced by low-income urban residents in their everyday lives.

Previous studies of sanitation in China have focused primarily on regional disparities in sanitation infrastructure provision or the technical, 'hard' aspects thereof. Disparities in basic sanitation provision - as well as in the quality of sanitation infrastructure - exist between the coastal areas and Inner and Western China as well as between urban and rural areas; for instance, it is estimated that 74 per cent of people in urban areas have access to improved sanitation, compared to 56 per cent in rural areas. ${ }^{5}$ Pointing out the problems associated with the adoption of centralised sewer-based systems in fast-growing, often water-scarce urban contexts, scholars have explored potential alternatives, such as decentralised and dry sanitation systems. 6 Yet despite the country's rapid economic development and its remarkable advances in the provision of improved sanitation, the percentage of urban residents in China forced to defecate in the open has been reported to have ogrown from 3 per cent to 6 per cent between 1990 and 2008 . ${ }^{7}$ More recent statistics estimating access to sanitation at 100 per cent ${ }^{8}$ seem to overlook the fate of

\footnotetext{
${ }^{3}$ For instance, Wissink, Bart, Ronald van Kempen, Yiping Fang and Si-ming Li (2012). "IItroduction-Living in Chinese Enclave Cities." Urban Geography 33(2): 161-166.

${ }^{4}$ Iossifova, Deljana (2015). "Borderland Urbanism: seeing between enclaves." Urban Geography 36(1): 90-108.

${ }^{5}$ Shen, Dajun (2006). Access to Water and Sanitation in China: History, current situation and challenges. Human Development Report Office Occasional Paper, United Nations Development Programme, Yang, Hong, Jim A Wright and Stephen W Gundry (2012). "Water: Improve access to sanitation in China." Nature 488(7409): 32.

${ }^{6}$ For instance, Medilanski, Edi, Liang Chuan, Hans-Joachim Mosler, Roland Schertenleib and Tove Larsen (2007). "Identifying the Institutional Decision Process to Introduce Decentralized Sanitation in the City of Kunming (China)." Environmental Management 39(5): 648-662, Flores, Amparo, Arno Rosemarin and Richard Fenner (2009). "Evaluating the Sustainability of an Innovative Dry Sanitation (Ecosan) System in China as Compared to a Conventional Waterborne Sanitation System." Proceedings of the Water Environment Federation 2009(8): 6734-6751, McConville, Jennifer and Arno Rosemarin (2011). Urine diversion dry toilets in multi-storey buildings: Erdos City, Inner Mongolia Autonomous Region, China. Stockholm, Sustainable Sanitation Alliance,

${ }^{7}$ World Health Organization and UNICEF (2010). Progress on Sanitation and Drinking-Water: 2010 Update. Switzerland, World Health Organization and UNICEF.

${ }^{8}$ UNICEF and World Health Organization (2013). Progress on Sanitation and Drinking-Water - 2013 Update. Switzerland, World Health Organization and UNICEF.
} 
rural-to-urban miogrants and low-income urban residents. ${ }^{9}$ These gुroups - among them a rapidly increasing proportion of senior citizens - suffer discrimination and exclusion in many areas of their everyday lives: health, housing and education provision are but a few. ${ }^{10}$ The perception of diveroging sanitation practices of low-income urban residents, who are excluded from access to mainstream, modern sanitation infrastructure, may therefore further exacerbate the experience of existing and potential sociomaterial inequalities.

This paper seeks to draw attention to the 'soft' aspects of everyday sanitation. Sanitation is embedded in the everyday in that it connects, in the words of McFarlane and colleagues, "body, infrastructure, city, health, education, livelihood, social relations, private-public relations and modernity." Everyday sanitation, here, begुins to locate experiences 'on the gुround' within a nexus of larger, complex transitions in cultural beliefs, social norms, spatial expectations, ecological requirements and economic drivers. This research builds on the understanding that everyday sanitation practices and the perceptions of these practices are manifestations of socio-material inequalities. Therefore, the experience of everyday sanitation offers a suitable lens through which to explore existing and emeroging socio-spatial differentiation under conditions of rapid urban development in Shanghai.

The next section provides a brief history of sanitation and modernisation in urban China. This is followed by an outline of the research approach and an account of the sanitation experiences of low-income urban residents in two inner-city neighbourhoods in Shanghai. The article concludes with the aroument that the coexistence of different sanitation systems and therefore practices as a result of rapid urban development and transformation is closely linked with processes of differentiation and stigmatisation, with implications for the individual experience of the everyday as well as the longer-term trajectories of maroginalised urban residents.

\section{MODERNISING SANITATION IN URBAN CHINA}

China's traditional agriculture was based around human waste and coupled animal and plant production. ${ }^{12}$ Human waste was considered a valuable commodity. ${ }^{13}$ In a closed loop system,

\footnotetext{
${ }^{9}$ Chai, Joseph CH and B Karin Chai (1997). "China's floating population and its implications." International Journal of Social Economics 24(7/8/9): 1038-1051.

${ }^{10}$ See Li, Bingqi (2004) "Urban Social Exclusion in Transitional China." CASEpaper 82. Tonģ, HongyMei, Daniel W L. Lai, Qun Zeng and WenYan Xu (20II). "Effects of Social Exclusion on Depressive Symptoms: Elderly Chinese Living Alone in Shanghai, China." Journal of Cross-Cultural Gerontology 26(4): 349-364, Liu, Li-Juan, Yun-Feng Fu, Li Qu and Yue Wang (2014). "Home Health Care Needs and Willingness to Pay for Home Health Care Among the Empty-nest Elderly in Shanghai, China." International Journal of Gerontology 8(1): 31-36, Luo, Weixiang and Yu Xie (2014). "Socio-economic disparities in mortality among the elderly in China." Population Studies 68(3): 305-320, McFarlane, Colin, Renu Desai and Steve Graham (2014). "Informal Urban Sanitation: Everyday Life, Poverty, and Comparison." Annals of the Association of American Geographers 104(5): 989-1011.

"McFarlane, Colin, Renu Desai and Steve Graham (2014). "Informal Urban Sanitation: Everyday Life, Poverty, and Comparison." Annals of the Association of American Geographers 104(5): 989-1011.

${ }^{12}$ Luo, Shiming (2002). The Utilization of Human Excreta in Chinese Agriculture and the Challenge Faced. EcoSanRes.
} 
households collected waste in terracotta jars with air-tight seals. These were emptied into special carts in the early morningुs, transported to the closest canal and shipped to the countryside on boats. Mixed with other waste and composted, human waste was used as organic fertiliser in the production of food. ${ }^{14}$

The collection and disposal of human waste in cities was carried out without any attempt to conceal what a Western observer described as its 'more nauseating aspects, except where such action has been influenced by foreionners. ${ }^{15}$. Foreiogn settlements are said to have created a model for the development of modern waste management in China. ${ }^{16} \mathrm{~A}$ first hygiene campaiogn was organised by Shanghai's Public Health Bureau in 1928. The municipality expelled impoverished 'hut dwellers' (mostly rural-to-urban migrants) from the international settlement and urgeed its urban citizens to clean their work spaces and residences in order to create a healthy population and sanitary city - to 'construct an orderly urban society' and 'reorganise urban space.'.

However, another Western observer in the 1930s commented: "until plumbers can devise some method of flushing a toilet so that the human fertilizer will not be sluiced into sewers where it is lost to the hungry soil that needs it so urgyently, the development of the plumbing business in China will necessarily lag far behind any other modern industry.' The use of sanitary plumbing, according to this source, 'does violence to the instincts of the Chinese' and 'many who live in modern Shanghai apartments often flush a toilet with a feeling of guilt and regret at the waste of fertilizer which would add to the production of a bean field or bring blooms to a flower gुarden'. ${ }^{\prime 8}$ In the late 1960s, the collection of human waste as traditionally practiced was abandoned over hygiene considerations in most areas of Shanghai. Where households had no access to the modern sewage system, the government installed central excrement collection stations in neighbourhoods. Now, residents had to carry their night pots to an excrement collection station nearby and dispose of their waste themselves. Urban redevelopment has led to the steady decline of excrement collection stations in the city, but their number stands still at approximately 2,000 across Shanghail (see Figure 1, Figure 2). Some rely on septic tanks; others dischargye directly into the municipal sewage system.

\footnotetext{
${ }^{13}$ Crow, Carl (1937). The Chinese are like that. New York and London, Harper \& Brothers.

${ }^{14}$ King, Franklin Hiram (19l1). Farmers of forty centuries: or, Permanent agriculture in China, Korea and Japan. Madison, WI, Mrs F H King.

${ }^{15}$ Crow, Carl (1937). The Chinese are like that. New York and London, Harper \& Brothers.

${ }^{16}$ Tong, Cheuk-kei (2009). Municipal waste management in Shanghai, 1866-1949. Master of Philosophy, The University of Hong Kong.

${ }^{17}$ Nakajima, Chieko (2008). "Health and Hygiene in Mass Mobilization: Hygiene Campaign in Shanghai, 1920-1945." Twentieth-Century China 34(1): 42-72.

${ }^{18}$ Crow, Carl (1937). The Chinese are like that. New York and London, Harper \& Brothers.

${ }^{19}$ Assuming that one excrement collection station serves some 500 - 800 people, this number suggests that a minimum of 1,000,000 people in Shanghai - over four per cent of the total registered resident population continue to rely on night pots and central excrement
} 


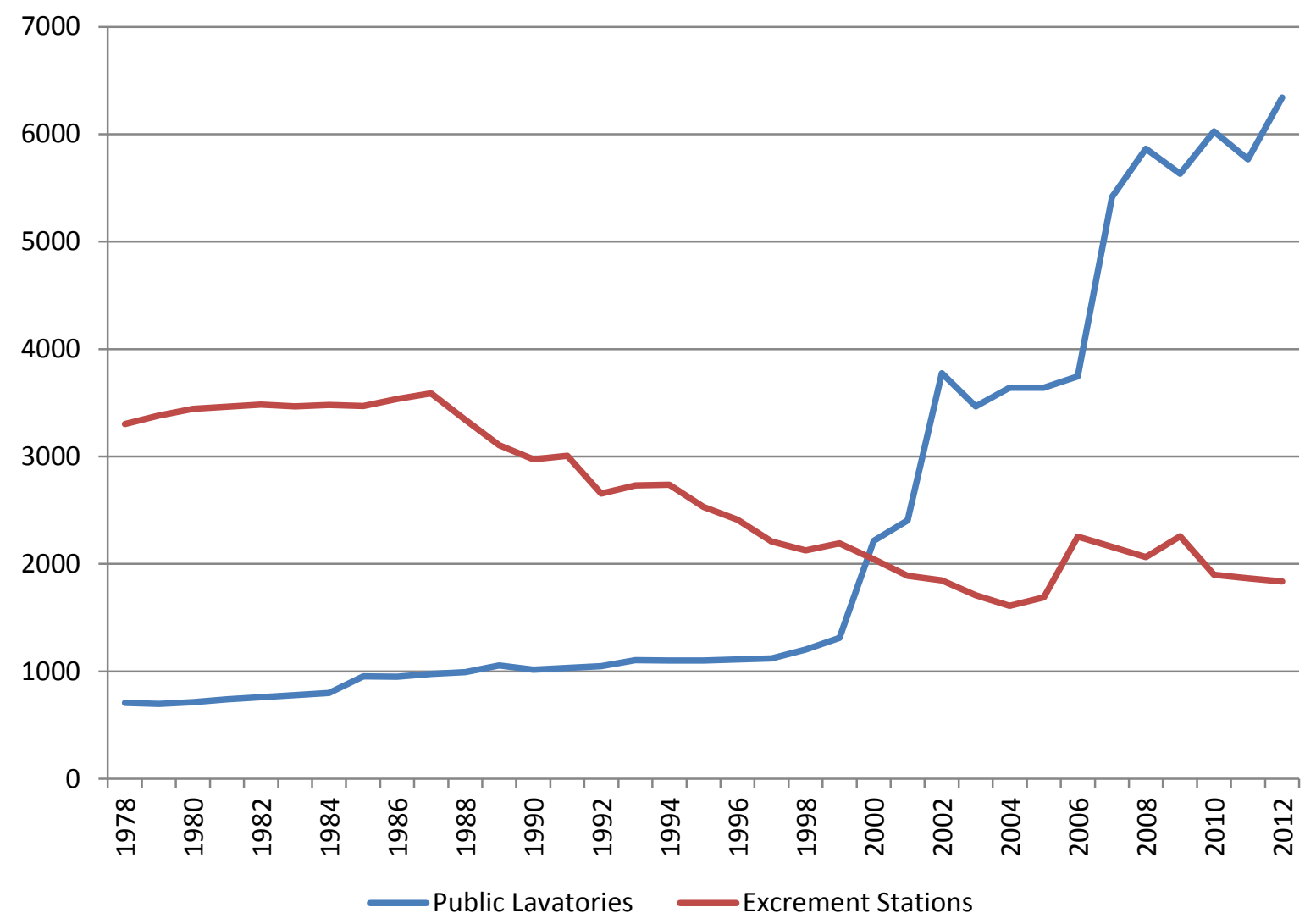

Figure 1: Growing number of public lavatories and shrinking number of excrement stations in Shanghai. Source: Shanghai Statistical Yearbook $2012^{20}$

Once China opened its doors to the West in the early 1980s, Shangुhai's gुovernment recognnised the lack of publicly accessible toilets as an urgent challenge. Since then, and especially in view of the Shanghhai World Expo 2010, enormous improvements have been made, as indicated in Figure 1. Public toilet blocks continue to be constructed and maintained by the municipal government, although a few charge a small amount (1 RMB; app. 0.16 USD) for their use. In the near future, the city plans to invest in the installation of flush toilets for residents of old residential areas that are not slated for redevelopment. ${ }^{2 .}$

Over the past decades, China has experienced a de-coupling of human waste and animal and plant production. As in other developing countries, the state seeks to attract investment and to implement various forms of infrastructure deemed appropriate for globalising service and financial industries. Urbanisation and growing labour costs have contributed to the sharp decline

collection as their main sanitation infrastructure. This estimate excludes a substantial number of unregistered rural-to-urban migrants who are very likely to depend on this same sanitation infrastructure.

20 Shangुhai Municipal Statistics Bureau (2013). Shangुhai Statistical Yearbook 2012, Beijing: China Statistics Press.

${ }^{21}$ Email correspondence with official at Shanghai Public Health Bureau, August 2013. 
of recycling rates for orgुanic materials in aogriculture and increasingyly less sustainable methods of food production. ${ }^{22}$ Despite being energy-intensive, in that they require fresh water, sewagye treatment, sewers and the replacement of oroganic with inoroganic fertilisers, water closets are now considered the most progressive and hyguienic option to deal with human waste. Today, according to a local official, the city is concerned with two major tasks: extending the opening hours of public toilets (currently, most close at 9 pm); and providing information on their location. ${ }^{23}$ The government has addressed the latter by installing city-wide siognaoge and launching the highly successful Shanghai Toilet Guide. This cellphone application locates the closest public facility one of currently 8,000 - and informs users about the availability of toilet paper and Westernstyle toilets. $^{24}$

However, not everyone has access to mainstream sanitation facilities and diverơing sanitation practices coexist. How this contributes to further socio-spatial differentiation within the context of contemporary Shanghai - and urban China more gुenerally - remains a relatively new and unexplored topic. The following sections will address this gap in providing an initial overview of the emeroging issues around everyday sanitation infrastructure and practices under conditions of high-speed urban development in contemporary Shangुhai.

\section{METHODOLOGY}

Following Chambers' call to 'put the last first', ${ }^{25}$ the research approach moves away from surveys based on pre-conceived survey questions and attempts, instead, to sketch the perspectives of low-income, maroginalised urban residents in the contemporary city. This more intimate view may contribute to a more complete understanding of the short- and long-term multi-dimensional issues that may result from uneven urban development and diverging sanitation practices in seemingly sanitised Shanghai; it may help to formulate timely directions for further research around urban sanitation in China in the future.

The field research was carried out over four weeks in July 2013 in several low-income areas in Shanghai. In order to develop a better understanding of the impact of coexistence between different spatial typologies and social groups on perceptions and practices of sanitation, two areas were selected on the basis of their spatial characteristics (i.e., old neighbourhoods nearby to new-built residential compounds) and social mix of inhabitants (i.e., long-term, low-income

\footnotetext{
${ }^{22}$ Natural nutrients accounted for only 35\% at the begुinning of this century. Ju, Xiaotang, Fusuo Zhang, Xuemei Bao, V. Römheld and M. Roelcke (2005). "Utilization and managुement of orgुanic wastes in Chinese agriculture: Past, present and perspectives." Science in China Series C: Life Sciences 48(2): 965-979.

23 Email correspondence with official at Shanghai Public Health Bureau, August 2013.

${ }^{24}$ Griffiths, James. (2013, 21 March). "In Shanghai? Need to pee? There's an app for that." Retrieved 21 July, 2013, from http://shanghhaiist.com/2013/03/21/shangुhai_toilet_gुuide_app_directs_users_where_to_pee_in_worlds_largुest_city.php.

${ }^{25}$ See Chambers, Robert (1983). Rural development: Putting the last first, Longyman London. Of course, Chambers' work was predominantly concerned with the rural context.
} 
urban residents and recent rural-to-urban migrants versus urban middle-class residents). In both areas, the majority of residents lacked access to flush toilets; they used night pots and emptied them at allocated neighbourhood excrement collection stations (see Figure 2).

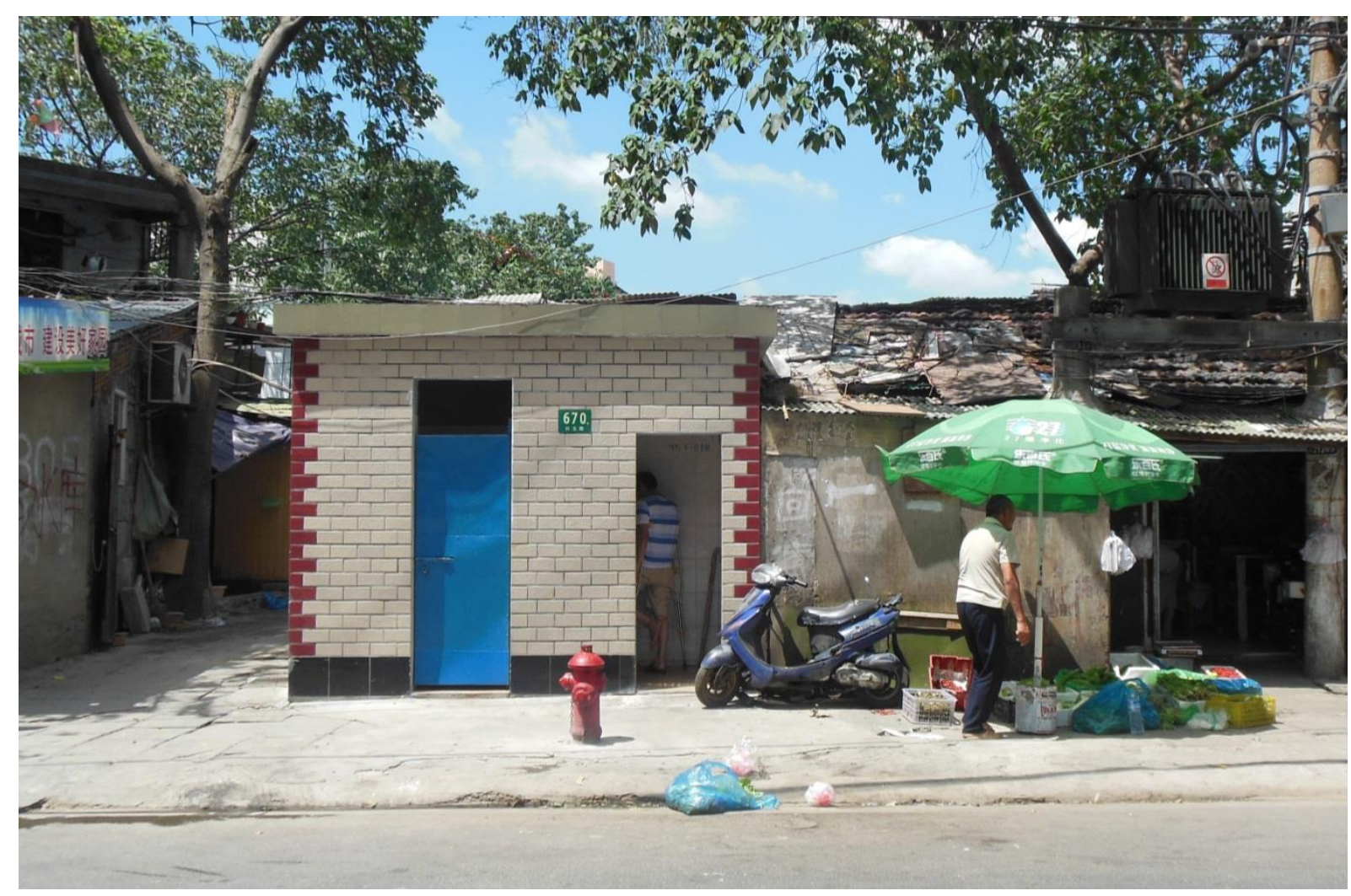

Figure 2: Central excrement collection station, Shanghai. Photograph: the author, 2013.

One case study area, Caojiacun, was demolished at the end of 2014. At the time of the field research, it was home to an older generation of retired or laid-off workers as well as recent rural-to-urban migrants. It had been established around a century ago and was known as a typical Subeineighbourhood. ${ }^{26}$ Ever since redevelopment of the wider area begुan in the late 1990s and this neighhourhood was surrounded by an ever-growing number of high-rise gुated communities for the new middle-class, residents were anxiously awaiting the demolition of their neighbourhood and their resettlement to newly-built flats elsewhere.

The other case study area was established on unwanted land, the site of a former mass grave, in the early 1940s, when some 4,000 poor families from all over the country settled here. In the mid-1990s, private developers bought the land north of the narrow street - Huining Lu - that runs through the neighbourhood, demolished existing housing and replaced it with a gated high-

\footnotetext{
${ }^{26}$ During the last century, migrants from Subeiwere linked with notions of poverty and rural backwardness and confined to Subei settlements on the edges of the formal city. See Honig, Emily (1992). Creating Chinese Ethnicity: Subei People in Shanghai, 1850-1980. New Haven, CT, Yale University Press.
} 
rise compound. Attached to the walls of a state-owned factory, the remaining houses to the south of the street remained untouched.

It should be noted that the research reported here was conducted as part of a scoping study aiming to develop a more comprehensive understanding of sanitation conditions and practices in low-income neighbourhoods. The research adopted a larggely participatory methodology, paying special attention not to inconvenience research participants or make them feel uncomfortable in any way. Unlike conditions elsewhere, ${ }^{27}$ sanitation is only beginning to be constructed as a taboo subject in China and it can be said that people are still generally happy to discuss the subject without inhibition. We approached potential interviewees informally and conversations took place in a rather casual manner, allowing participants to choose freely how much or how little of their sanitation experiences to share. Although we had planned to speak to low-income urban residents, middle-class urban residents and rural-to-urban migrants, due to time constraints we chose to focus mainly on the first group. This paper is based on in-depth, open-ended interviews with 20 low-income urban residents of the two case study neighbourhoods.

Although we were mindful to focus the interviews on participants' experience and perceptions of sanitation infrastructure and practices, it should be noted that owing to the nature of the selected case study areas (i.e., neighbourhoods slated for future redevelopment or currently on the verge of demolition and displacement), participants often diverted the discussion to their disgruntlement with processes of urban development, land grab, forced eviction, imprisonment and other grave themes - which, although of great importance, cannot be discussed in detail within the context of this article. They require appropriate treatment and in-depth study in the future.

\section{EVERYDAY PRACTICES OF SANITATION AND DIFFERENTIATION}

This section reports on the main sanitation-related concerns of research participants. Those most adversely affected by exclusion from access to mainstream sanitation infrastructure appear to be the elderly, low-income urban residents and rural-to-urban migrrants.

\footnotetext{
${ }^{27}$ See, for instance, Jewitt, Sarah (2011). "Geographies of shit: Spatial and temporal variations in attitudes towards human waste." Progress in Human Geography 35(5): 608-626, Jewitt, Sarah and Harriet Ryley (2014). "It's a girl thing: Menstruation, school attendance, spatial mobility and wider gender inequalities in Kenya." Geoforum 56(0): 137-147, McFarlane, Colin, Renu Desai and Steve Graham (2014). "Informal Urban Sanitation: Everyday Life, Poverty, and Comparison." Annals of the Association of American Geographers 104(5): 989-1011, ibid., Srivastava, Vinay Kumar (2014). "On Sanitation: A Memory Ethnography." Social Change 44(2): 275-290.

${ }^{27}$ Joshi, Deepa, Ben Fawcett and Fouzia Mannan (2011). "Health, hygiene and appropriate sanitation: experiences and perceptions of the urban poor." Environment and Urbanization 23(1): 91-111.
} 


\section{Isolated Ageing}

Economic progress and rising expectations have had an impact on family structure and traditional living arrangements. ${ }^{28}$ Once undisputed - traditional China has frequently been described as a "gुerontocracy' ${ }^{29}$ - the authority of the elderly is begुinning to fade. The formerly common multigeneration household model is breaking up and the elderly are frequently left to live alone in old and impoverished neighbourhoods. ${ }^{30}$

Mr and Mrs Huano ${ }^{31}$, typical Caojiacun residents, are both in their late 80 s. They remember the times when theirs used to be a quiet neighbourhood for families with children. They used to place their household's night pot in front of the entrance to their house, so that its contents could be collected early in the morning. The excrement was then transported onto a boat on the Suzhou Creek nearby and shipped to the countryside, where it was sold to farmers. 'This system was much more organic', they say; 'the fertilisers they use nowadays are poison. ${ }^{32}$

But once the central excrement collection system was introduced in their neighbourhood some twenty years ago, the Huangs, then in their late 60 s, installed a flush toilet. There is no door to the small room under the stairs where the bowl is located and they only use it to empty their night pot, which they prefer and continue to use. They say that having the flush toilet in the house made life more convenient for them as they grew older; it saved them the daily trips to the excrement collection station.

But not everyone in the neighbourhood is as lucky. Mrs Wongु's woes are representative of those of many: also in her 80s, she lives alone in a small house only a couple of lanes away. Her husband passed away and her children are white-collar professionals and live in modern highrise buildings far away. She is too old and ill to make the journey to their homes. In the past, it was common for them to come for dinner at her house on Saturdays. The whole family would also come together on special occasions, such as Chinese New Year. But with time, these visits became more and more sporadic and have ceased almost entirely ever since her grandchildren reached their teen-agge years. 'I can't afford a modern toilet', Mrs Wong laments. 33 'And you know how it is: when the children come to visit, after two hours or so one will have to go to the toilet.

\footnotetext{
${ }^{28}$ Lei, Xiaoyan, John Strauss, Meng Tien and Yaohui Zhao (2011) "Living arrangements of the elderly in China: Evidence from CHARLS.", Sun, Xiaojie, Henry Lucas, Qingyue Meng and Yaoguang Zhang (2011). "Associations between living arrangements and health-related quality of life of urban elderly people: a study from China." Quality of Life Research 20(3): 359-369.

${ }^{29}$ Cheung, L. Y., E. R. Cho, D. Lum, T. Y. Tang and H. B. Yau (1980). "The Chinese elderly and family structure: implications for health care." Public Health Reports 95(5): 491-495.

${ }^{30}$ Liu, Li-Juan, Yun-Feng Fu, Li Qu and Yue Wang (2014). "Home Health Care Needs and Willingness to Pay for Home Health Care Among the Empty-nest Elderly in Shanghai, China." International Journal of Gerontology 8(I): 31-36.

${ }^{31}$ All names have been changed in the interest of interview participants.

${ }^{32}$ Interview with Mr and Mrs Huang, July 2013

${ }^{33}$ Interview with Mrs Wong, July 2013
} 
But they're scared and disgusted. They don't know how to use a night pot any more. So they don't come. They call, but they won't visit'.

\section{Disputed Ownership}

Mr Hu was born in the Huining Lu neighbourhood in 1946. He and his family shared his parents' tiny house with them until their recent death. Then, following a long dispute among the three surviving sons, the house was divided into three parts: one third for each of the brothers. Mr Hu and his wife have had to live without private access to tap water ever since because the only available tap is located in part of the house belonging to one of the brothers. In this situation, he laments, it is difficult to have friends and family come and visit; no one will visit a place without running water and a toilet'. ${ }^{34}$ Luckily, the neighbourhood committee (juweihui) sponsored the external tidying-up and painting of all homes in Huining Lu in expectation of the Shanghai EXPO 2010. As part of the campaiogn, a block of public water taps was installed on the pavement across the street (see Figure 3). Although this was gुenerally considered a gुreat improvement, having to cross the street when in need of water made the predominantly elderly residents feel unsafe. Reportedly, speeding cars had caused many accidents; residents experienced them as encroaching upon their common space, the street.

\footnotetext{
${ }^{34}$ Interview with $\mathrm{Mr} \mathrm{Hu}$, July 2014
} 


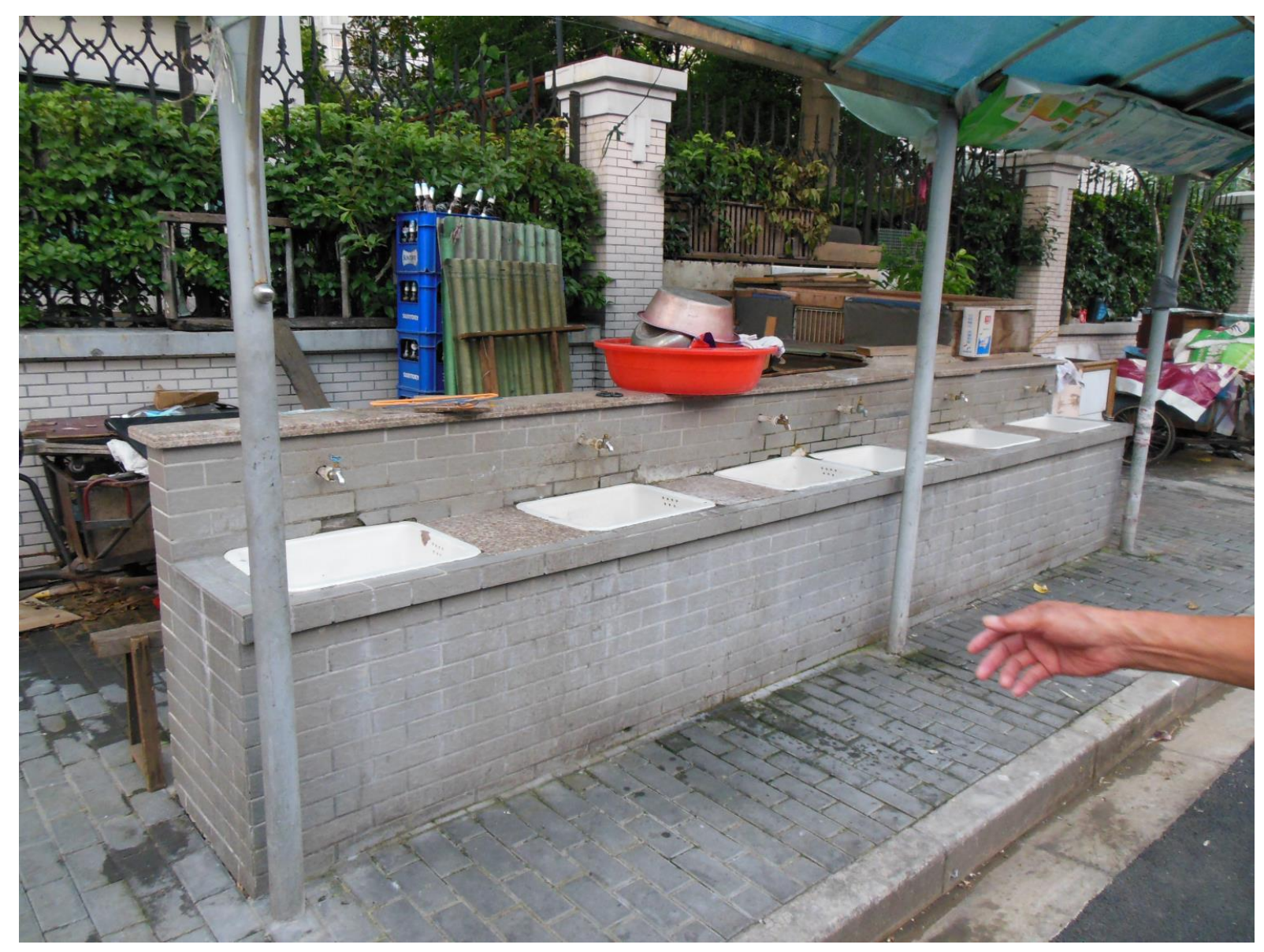

Figure 3: Public water taps, built for local residents in expectation of the EXPO 2010. Photo: the author, 2013.

\section{Conditional Commitment}

For Mr Jiang, next door, the Shanghai Expo 2010 came as a blessing. Like many others, he invested his savings to add an extra storey to his house without applying for a building permit. 'The government', he says, 'was too busy renovating the city to monitor what we poor people did during this time. ${ }^{35}$ Although his son graduated from a renowned Shanghai university, he has been unable to find employment appropriate to his qualifications and now works as a shop clerk. Mr Jiang, who had spent some time in prison several decades earlier, attributes this to the background checks conducted by respective employers. But it is the family's living conditions that impact on the son's marriagुe prospects: 'There have been many gुillfriends,' Mr Jiang explains, but 'the moment they come home to meet us, they run. They see it's a small house, and, although we have water, we still have to use the night pot. You eat here and you shit here, you see. Same place. There is no toilet. Young women want their own private toilet nowadays. We can't offer that. So they run' (see Figure 4).

\footnotetext{
${ }^{35}$ Interview with Mr Jiang, July 2013
} 


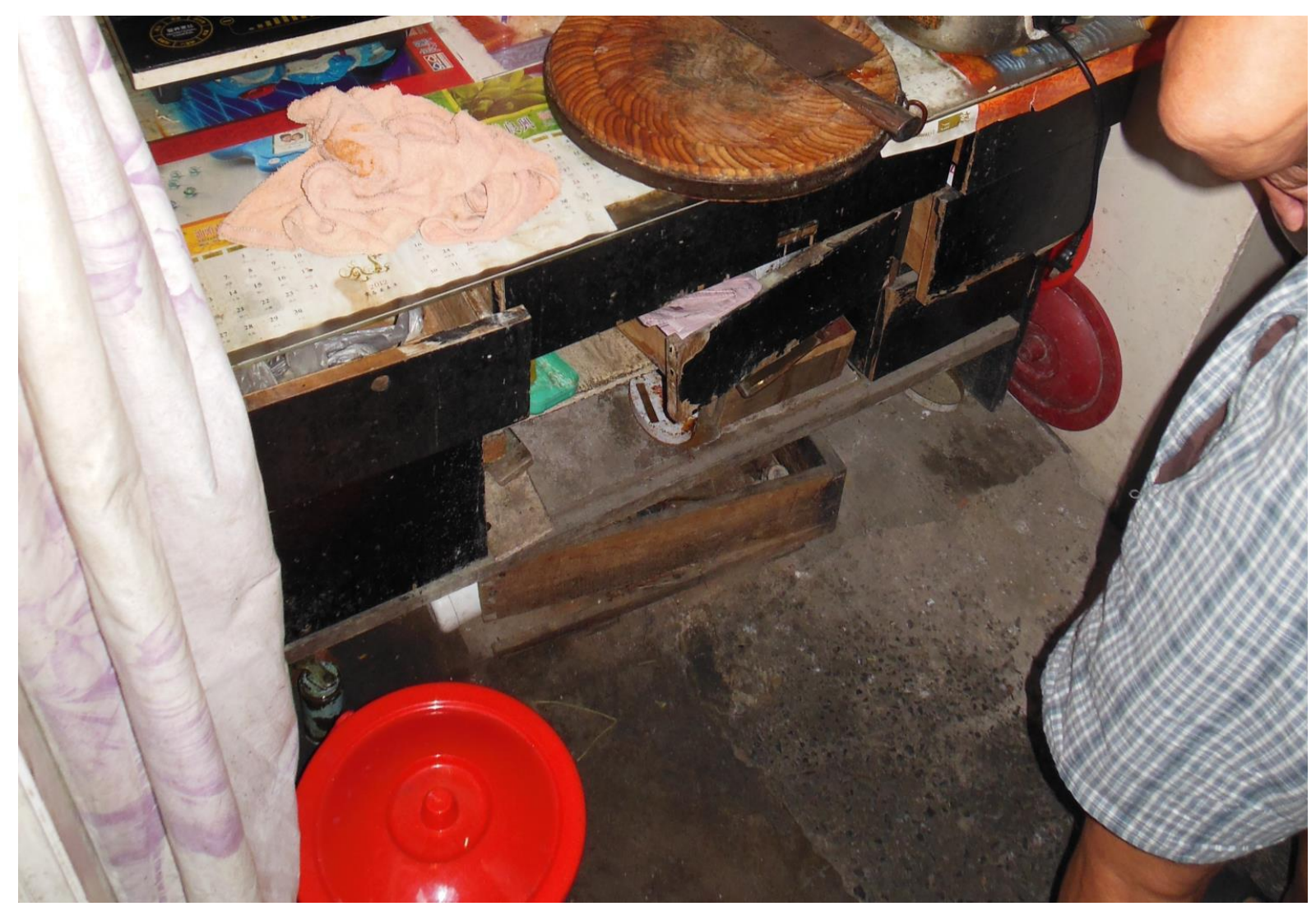

Figure 4: 'You eat here and you shit here'. Night pot can be seen in the lower left corner, sitting next to the cooking area in Mr Jiangु's small house. Photo: the author, July 2013.

This development marks a sharp transition from customs in the past. Mrs Chen, a neighbour in her late 50s, remembers what it was like to share a small house with her husband and his parents as a new bride in the 1980s: "In the beginning, it was awkward. Couples needed to get used to each other. Us women, we would send the men out and hide behind a curtain in the corner to use the night pot. The men would pay to use the bath house when they had to gुo... But with time, you get used to it. It's family. ${ }^{36}$

\section{Uncertain Futures}

A bit further down the road, Mr Zhu, in his late 50s, explains that the areas surrounding his neigh bourhood have been under redevelopment for much of the past ten years. ${ }^{37}$ He put his life on hold in expectation of his own, government-ordered relocation. Had he known that it would take this long, he says, he would have installed a flush toilet years ago. Looking around, he comments: 'Really, all people should have private toilets. This way, they won't disturb each other with sounds and smells. It is a lot more civilised to have a Western style toilet. Look at the new

\footnotetext{
${ }^{36}$ Interview with Mrs Chen, July 2013

37 Interview with Mr Zhu, July 2013.
} 
apartment buildings. They all have at least two Western style toilets in a flat. Now, that's human. It's not very civilised to shit where you eat'.

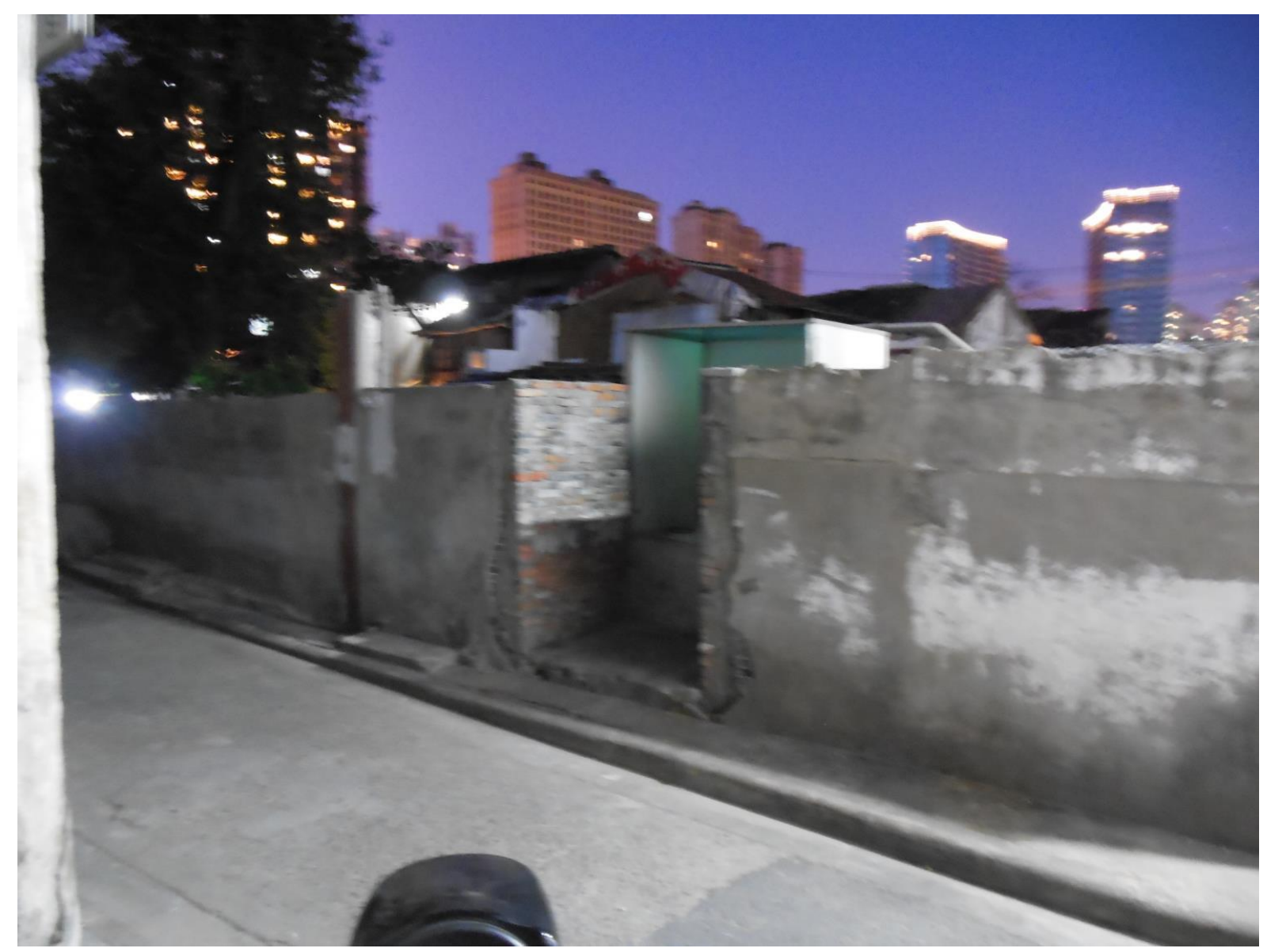

Figure 5: A 'temporary' excrement collection station amidst demolition and redevelopment near the city centre. Photograph: the author, 2013.

The Zhu family use night pots and they empty them into a septic tank a couple of hundred metres away. There used to be a proper central excrement collection station nearby, but the demolition company demolished it years earlier - 'probably by mistake', so Mr Zhu. The government installed a 'temporary' excrement collection station (see Figure 5) for the remaining population of low-income urban residents and migrant construction workers. The structure is now used as a collection station and public toilet: only a short walk from Shanghai's busy central business district, predominantly migrrant men, small children and sometimes women can be seen squatting above a hole in a raised concrete slab, surrounded only by three polycarbonate partition walls.

\section{Redefined Urbanity}

Because rural-to-urban migrants have limited access to the housing market and affordable housing in cities like Shanghai, many live in cramped conditions in low-income neighbourhoods or 
in basic housing provided by their employer. ${ }^{38}$ Consequently, they have limited access to modern sanitation and therefore rely on central excrement collection stations or public facilities., Among many longer term urban dwellers there seems to be an ingrained attitude, based on both observation and perception, that rural-to-urban migrants never develop the habit of using a toilet and that therefore, they fail to teach their children to use toilets. "Kids just take their pants off and shit in the middle of the street; and they don't even wipe their arses after. Shanghainese kids would never do that!' says Mr Huang. ${ }^{39}$ Although they often share sanitation infrastructure with their migrant neighbours, many urban dwellers distinguish between their own practices - in their view, urban and sophisticated - and those of migrants. Representative of many, Mrs Wong says: 'There are too many miogrants here now, and they don't know how to do their 'business properly; they make the neighbourhood dirty because they come from the countryside. The juweihuistopped making their rounds. They don't care anymore. ${ }^{40}$ In the past, representatives of these local neighhbourhood committees (juweihui) used to check the sanitary status of all homes at least once a week to make sure that neighbourhoods were clean and up to the government's hygiene standard. Hardly trying to disoguise her hostility, Mrs Wong continues as she points at a group of migrants passing by the window: 'Look at them. They are not very well educated. Once local residents started moving out and migrants begुan to move in, ten-fifteen years agुo, it all started going down-hill. Between cars and walls, you will always find shit in the morning. They pee and shit everywhere'.

\section{CONCLUSIONS}

This article offers an initial exploration of the role of diverging everyday practices of sanitation in the negुotiation of urban coexistence in transitioning Shanghai. In particular, it explores how, under conditions of rapid urban development and therefore uneven access to advanced sanitation infrastructure, the practice of sanitation is experienced by low-income urban residents in their everyday.

Drawing attention to the 'soft' aspects of everyday sanitation, the paper shows that everyday sanitation practices and people's perceptions of them are, indeed, manifestations of sociomaterial inequalities. China's transition from a closed-loop sanitation system to the, quite possibly unsustainable, current system of human waste disposal is rapidly taking shape in large parts of the country's cities. However, the adoption of mainstream sanitation infrastructure happens at different speeds and not all areas (and people) are evenly covered. Just as old and new neighhbourhoods continue to exist side-by-side, so do different sanitation systems and therefore

\footnotetext{
${ }^{38}$ For instance, see Li, Zhigang and Fulong Wu (2013). "Residential Satisfaction in China's Informal Settlements: A Case Study of Beijing, Shanghai, and Guangzzhou." Urban Geography 34(7): 923-949, Wu, Fulong, Fangzhu Zhang and Chris Webster (2013). Rural Migrants in Urban China: Enclaves and Transient Urbanism. London and New York, Routledge.

${ }^{39}$ Interview with Mrs Huang, July 2013

${ }^{40}$ Interview with Mrs Wong, July 2013
} 
practices. Those most adversely affected by exclusion from access to mainstream sanitation infrastructure appear to be the elderly, low-income urban residents and rural-to-urban migrants.

Frequently left to live alone in old and impoverished neighbourhoods, the elderly can find it difficult to access central excrement collection stations to dispose of their waste. They prefer the possibility to do so within the confines of their home, even if that means, as in the example given earlier, using makeshift water closets that are not connected to the sewagge system. Younger members of the family can have expectations of the kind and quality of the sanitation infrastructure they are willing to use. As a result, they can be reluctant to visit the elderly for prolonged periods. This can have direct negative implications for family relations and ties. Furthermore, young men, in particular, struggole to meet the ever-higher expectations of potential future wives; those without access to mainstream sanitation are often unable to find a spouse.

The relentless redevelopment of urban areas has led to an increased awareness of property and value among all urban residents, regardless of their socioeconomic status. Property ownership is often disputed and leads to broken family ties as already small homes are physically divided between family members, leaving behind some without access to running water. For those awaiting gुovernment-ordered and development-induced relocation, long-term, lasting uncertainty about the timing of their relocation serves to prevent them from investing in possible improvements to their homes and in upgraded sanitation facilities, in particular.

Although sanitation practices in the past had mostly ceased to be the subject of prescribed rituals or taboos in China - manifested vividly in the occasional lack of doors to public or institutional toilets, for instance - the current race for urban development and gुlobalisation seems to be contributing to a rapid cultural shift and renewed consciousness about what does or does not constitute 'appropriate' sanitation. Indeed, just as Joshi, Fawcett et al. observe elsewhere, there seems to be "universal aspiration among a diverse group of the urban poor to facilities and services that provide personal privacy and dignity and ensure a clean and healthy living environment'; what is 'appropriate' is determined by 'local culture, individual needs and preferences, and by what is seen and learnt from the media and from one another. ${ }^{41}$

Lastly, many rural-to-urban migrants live under sub-standard conditions in low-income neighhbourhoods with limited access to modern sanitation. They are blamed for the decline of the urban living environment by long-term urban residents, who develop categories to describe their own sanitation practices as urban and sophisticated - in contrast to those uneducated and dirty of rural-to-urban migrants.

Advances in technology and divergुing everyday practices of personal hygiene are therefore situated at the core of urban sociospatial differentiation, inequality, exclusion and discrimination.

\footnotetext{
${ }^{41}$ Joshi, Deepa, Ben Fawcett and Fouzia Mannan (2011). "Health, hyciene and appropriate sanitation: experiences and perceptions of the urban poor." Environment and Urbanization 23(1): 91-111.
} 
Particularly affected in these neighbourhoods in Shanghai are rural-to-urban migrants and aggeing working-class residents who often lack access to 'improved' sanitation and suffer stigmatisation and social isolation. Future research should therefore examine how changing sanitation cultures under urban development and diveroging sanitation practices affect family ties, social relations and sociospatial integrration to identify vulnerable grroups in different urban settingss. Specific research questions might be how and why the everyday sanitation practices of rural-to-urban migrants differ from those of urban long-term urban residents; and what the implications for their sociospatial integration might be. Furthermore, future research should address the physical and social consequences of lack of access to modern sanitation for people above 65 in a rapidly aggeing society, determining likely implications for policy, planning and desiogn.

\section{ACKNOWLEDGEMENTS}

The research was supported by the Research Stimulation Fund, University of Manchester. As always, thank you to Jaye Shen who worked with me in the field. The critical suggestions of two anonymous reviewers and the editors are highly appreciated. I am also gुrateful for feedback received following presentations at the RGS-IBG Annual International Conference 2013; the $6^{\text {th }}$ International Forum for Contemporary Chinese Studies (IFCCS 6) Joint Conference; the University of Nottingham, Georg-August-Universität Göttingen, Swiss Federal Institute of Technologyy, and University of Manchester.

\section{REFERENCES}

Chai, Joseph CH and B Karin Chai (1997). "China’s floating population and its implications." International Journal of Social Economics 24(7/8/9): 1038-1051.

Chambers, Robert (1983). Rural development: Putting the last first, Longman London.

Cheung, L. Y., E. R. Cho, D. Lum, T. Y. Tang and H. B. Yau (1980). "The Chinese elderly and family structure: implications for health care." Public Health Reports 95(5): 491-495.

Crow, Carl (1937). The Chinese are like that. New York and London, Harper \& Brothers.

Flores, Amparo, Arno Rosemarin and Richard Fenner (2009). "Evaluating the Sustainability of an Innovative Dry Sanitation (Ecosan) System in China as Compared to a Conventional Waterborne Sanitation System." Proceedings of the Water Environment Federation 2009(8): 6734-6751.

Griffiths, James. (2013, 21 March). "In Shanghai? Need to pee? There's an app for that." Retrieved 21 July, 2013, from http://shangुhaiist.com/2013/03/21/shanghai_toilet_guide_app_directs_users_where_to_pe e_in_worlds_largyest_city.php.

He, Shenjing (2007). "State-sponsored Gentrification under Market Transition: The Case of Shanghai." Urban Affairs Review 43(2): 171-198. 
He, Shenjing and Fulong Wu (2007). "Socio-spatial impacts of property-led redevelopment on China's urban neighbourhoods." Cities 24(3): 194-208.

Honig, Emily (1992). Creating Chinese Ethnicity: Subei People in Shanghai, 1850-1980. New Haven, CT, Yale University Press.

lossifova, Deljana (2015). "Borderland Urbanism: seeing between enclaves." Urban Geography 36(1): 90-108.

Jewitt, Sarah (2011). "Geographies of shit: Spatial and temporal variations in attitudes towards human waste." Progress in Human Geography 35(5): 608-626.

Jewitt, Sarah and Harriet Ryley (2014). "It's a gुirl thing: Menstruation, school attendance, spatial mobility and wider gender inequalities in Kenya." Geoforum 56(0): 137-147.

Joshi, Deepa, Ben Fawcett and Fouzia Mannan (2011). "Health, hygiene and appropriate sanitation: experiences and perceptions of the urban poor." Environment and Urbanization 23(1): 91-111.

Ju, Xiaotang, Fusuo Zhang, Xuemei Bao, V. Römheld and M. Roelcke (2005). "Utilization and managgement of organic wastes in Chinese agriculture: Past, present and perspectives." Science in China Series C: Life Sciences 48(2): 965-979.

King, Franklin Hiram (1911). Farmers of forty centuries: or, Permanent agriculture in China, Korea and Japan. Madison, WI, Mrs F H King.

Lei, Xiaoyan, John Strauss, Meng Tien and Yaohui Zhao (2011) "Living arrangements of the elderly in China: Evidence from CHARLS."

Li, Bingugi (2004) "Urban Social Exclusion in Transitional China." CASEpaper 82.

Li, Zhiggang and Fulong Wu (2013). "Residential Satisfaction in China's Informal Settlements: A Case Study of Beijing, Shanghai, and Guangुzhou." Urban Geography 34(7): 923-949.

Liu, Li-Juan, Yun-Feng Fu, Li Qu and Yue Wang (2014). "Home Health Care Needs and Willingुness to Pay for Home Health Care Among the Empty-nest Elderly in Shangुhai, China." International Journal of Gerontology 8(1): 31-36.

Luo, Shiming (2002). The Utilization of Human Excreta in Chinese Agriculture and the Challengye Faced. EcoSanRes.

Luo, Weixiang and Yu Xie (2014). "Socio-economic disparities in mortality among the elderly in China." Population Studies 68(3): 305-320.

McConville, Jennifer and Arno Rosemarin (2011). Urine diversion dry toilets in multi-storey buildingुs: Erdos City, Inner Mongुolia Autonomous Reģion, China. Stockholm, Sustainable Sanitation Alliance,

McFarlane, Colin, Renu Desai and Steve Graham (2014). "Informal Urban Sanitation: Everyday Life, Poverty, and Comparison." Annals of the Association of American Geographers 104(5): 9891011 . 
Medilanski, Edi, Liang Chuan, Hans-Joachim Mosler, Roland Schertenleib and Tove Larsen (2007). "Identifying the Institutional Decision Process to Introduce Decentralized Sanitation in the City of Kunming (China)." Environmental Management 39(5): 648-662.

Nakajima, Chieko (2008). "Health and Hygoiene in Mass Mobilization: Hygoiene Campaiogn in Shangुhai, 1920-1945." Twentieth-Century China 34(1): 42-72.

Shanghai Municipal Statistics Bureau (2013). Shangुhai Statistical Yearbook 2012, Beijing.: China Statistics Press.

Shen, Dajun (2006). Access to Water and Sanitation in China: History, current situation and challenges. Human Development Report Office Occasional Paper, United Nations Development Programme.

Srivastava, Vinay Kumar (2014). "On Sanitation: A Memory Ethnography." Social Change 44(2): 275-290.

Sun, Xiaojie, Henry Lucas, Qingyue Meng and Yaoguang Zhang (2011). "Associations between living arrangements and health-related quality of life of urban elderly people: a study from China." Quality of Life Research 20(3): 359-369.

Tong, Cheuk-kei (2009). Municipal waste managuement in Shanģhai, 1866-1949. Master of Philosophy, The University of Hong Kong.

Tong, HonģMei, DanielW L. Lai, Qun Zengु and WenYan Xu (2011). "Effects of Social Exclusion on Depressive Symptoms: Elderly Chinese Living Alone in Shanghai, China." Journal of Cross-Cultural Gerontology 26(4): 349-364.

UNICEF and World Health Organization (2013). Progress on Sanitation and Drinking-Water 2013 Update. Switzerland, World Health Orgुanization and UNICEF.

Wissink, Bart, Ronald van Kempen, Yiping Fang and Si-ming Li (2012). "Introduction-Living in Chinese Enclave Cities." Urban Geography 33(2): 161-166.

World Health Organization and UNICEF (2010). Progress on Sanitation and Drinking-Water: 2010 Update. Switzerland, World Health Orgुanization and UNICEF.

Wu, Fulong (2009). "Neo-urbanism in the making under China's market transition." City 13(4): 418-431.

Wu, Fulong (2010). "Gated and packarged suburbia: Packaging and branding Chinese suburban residential development." Cities 27(5): 385-396.

Wu, Fulong, Fangyzhu Zhang and Chris Webster (2013). "Informality and the Development and Demolition of Urban Villages in the Chinese Peri-urban Area." Urban Studies 50(10): 1919-1934. Wu, Fulong, Fangुzhu Zhang and Chris Webster (2013). Rural Migrrants in Urban China: Enclaves and Transient Urbanism. London and New York, Routledge. 
Wu, Qiyan, Jianquan Cheng, Guo Chen, Denial J Hammel and Xiaohui Wu (2014). "Socio-spatial differentiation and residential segregation in the Chinese city based on the 2000 communitylevel census data: A case study of the inner city of Nanjing." Cities 39: 109-119.

Yang, Hong, Jim A Wright and Stephen W Gundry (2012). "Water: Improve access to sanitation in China." Nature 488(7409): 32. 